\title{
Article
}

\section{Observation of nutrient uptake at the adaxial surface of leaves of tomato (Solanum lycopersicum) using Raman spectroscopy}

Butler, Holly J., Martin, Francis L, Roberts, Michael R., Adams, Steve and McAinsh, Martin R.

Available at http://clok.uclan.ac.uk/29782/

Butler, Holly J., Martin, Francis L ORCID: 0000-0001-8562-4944, Roberts, Michael R., Adams, Steve and McAinsh, Martin R. (2020) Observation of nutrient uptake at the adaxial surface of leaves of tomato (Solanum lycopersicum) using Raman spectroscopy. Analytical Letters, 53 (4). pp. 536 562. ISSN 0003-2719

It is advisable to refer to the publisher's version if you intend to cite from the work. http://dx.doi.org/10.1080/00032719.2019.1658199

For more information about UCLan's research in this area go to http://www.uclan.ac.uk/researchgroups/ and search for <name of research Group>.

For information about Research generally at UCLan please go to http://www.uclan.ac.uk/research/

All outputs in CLoK are protected by Intellectual Property Rights law, including Copyright law. Copyright, IPR and Moral Rights for the works on this site are retained by the individual authors and/or other copyright owners. Terms and conditions for use of this material are defined in the policies page. 
Observation of nutrient uptake at the adaxial surface of leaves of tomato (Solanum lycopersicum) using Raman spectroscopy

Holly J. Butlerabc*, Francis L. Martinad*, Michael R. Robertsa, Steve Adamse, Martin R. McAinsha*

a Lancaster Environment Centre, Lancaster University, Lancaster LA1 4YQ, UK

${ }_{b}$ Centre for Global Eco-Innovation, Lancaster Environment Centre, Lancaster University, Lancaster LAI 4YQ, UK

c WESTChem, Department of Pure and Applied Chemistry, Technology and Innovation Centre, University of Strathclyde, Glasgow G1 1RD, UK

dSchool of Pharmacy and Biomedical Sciences, University of Central Lancashire, Preston PR1 2HE, UK

e Plant Impact Plc, Rothamsted, West Common, Harpenden, Hertfordshire AL5 2JQ, UK

*Corresponding Author: Dr Holly J. Butler: holly.butler@strath.ac.uk

Prof. Francis L. Martin: flmartin@uclan.ac.uk

Dr Michael R. Roberts:m.r.roberts@lancaster.ac.uk

Dr Steve Adams: steve.adams@plantimpact.com

Dr Martin R. McAinsh: m.mcainsh@lancaster.ac.uk; Tel.: +44(0)1524 510553 


\begin{abstract}
Foliar application of nutrient fertilisers is standard practice in agricultural environments, and has been shown to increase crop yield and quality more efficiently and economically than soil-based fertilisers. The adsorption of macro- and micro-nutrients through the upper epidermis of leaves is largely species dependent; reliant upon penetration through the cuticle and stomata, and also upon the plant's ability to translocate the nutrient. Herein we describe a method to observe nitrate ( $\left.\mathrm{NO}_{3}-\right)$ uptake at the adaxial leaf surface to determine the efficacy of foliar fertilisers. We use Raman microspectroscopy as a sensitive approach to monitor NO3- associated vibrational modes, complemented by ion probe measurements and measurements of leaf nutrient status using flame atomic absorption spectroscopy. Results show that $\mathrm{NO}_{3}$ - uptake can be observed down to concentrations as low as $15 \mathrm{mM}$ using Raman microspectroscopy over a defined surface area, and that the rate of uptake can also be quantified using this approach. These observations could also infer information regarding the transport of other ions present in nitrate salts, such as calcium $(\mathrm{Ca})$, via the indirect monitoring of $\mathrm{NO}_{3}-$ specific bands. We believe that Raman microspectroscopy provides a novel method for monitoring nutrient movement throughout plant tissue, and provides a potential tool for nutrient screening.
\end{abstract}

\title{
Keywords:
}

Raman Spectroscopy, Nutrient Uptake, Food Security, Crop Screening.

\section{Background}


In order to produce optimum yield and quality, it is essential that crops receive adequate levels of macro- (N, P, K, Ca, Mg and S) and micro- (B, Cl, Cu, Fe, Mn, Mo, N and Zn) nutrients during cultivation. The application of nutrient fertilisers is a practice well-exercised through time, with three primary macronutrients, $\mathrm{N}, \mathrm{P}$ and $\mathrm{K}$ having the greatest immediate effect on crop yield (Roy 2006). In 2013, as much as $140 \mathrm{~kg}$ of nitrogen-based fertiliser was applied to each hectare of arable land in the UK as a prerequisite for cultivation (British survey of fertiliser practice 2014). Whilst this process has been shown to have positive impacts on overall crop yield, quality and shelf life; this is by no means an efficient process. Over-application of these nutrients does not meet the additional nutrient requirements of the crop, which can result in equally detrimental nutrient deficiencies of other macro- and micronutrients. Furthermore, as well as the considerable carbon footprint that is associated with fertiliser production, $\mathrm{N}$ losses through leaching and denitrification present a significant environmental impact to the land surrounding agricultural sites and the human water supply (Gooding 1992; Hillier 2009). Due to the threat of continued population growth, the maintenance of global food security demands a drastic increase in agricultural productivity and thus a movement away from such agricultural customs (Parry 2015).

An alternative approach is application of fertilisers via a foliar spray; where a single or mixture of solutions (as well as pesticides and herbicides) can be applied directly onto the leaf and fruit tissue (Swietlik 1984). It has been suggested that providing nutrients directly to the crop rather than the growth medium may reduce the volume of fertiliser required, presenting a more efficient process that may increase nutrient recovery rate in crops (Dixon 2003; Saleem 2013). Foliar fertiliser application also has the added benefit of reduced lag time between application and uptake by the plant, as well as overcoming issues surrounding poor absorption from nutrient complex in the soil (Alexander 1986; Fageria 2009). As the majority of fertiliser application protocols are soil-based, the analysis of nutrients in the soil 
has been particularly valuable to determine the nutrient availability in different environments (Jones Jr 2001). However, this is not always reflective of the uptake into the plant, as some nutrients are fixed within the soil and therefore not available for uptake, whilst some are only partially utilised, and some are readily lost within the environment (Roy 2006). By focusing upon foliar applications of nutrient fertiliser, it is possible to directly observe the effect of product formulation on net elemental uptake.

However, a number of significant factors inhibit the universal use of foliar sprays for the application of nutrients. The efficiency of foliar sprays is variable depending upon environmental conditions, the crop species and fertiliser formulations; all of which have substantial impact on nutrient penetration through the cuticle surface and subsequent translocation, see Fernàndez and Eichert (2009). As with soil application of fertilisers, environmental conditions such as humidity, temperature and light availability all can prevent the efficient uptake of nutrient at the leaf surface, due to the effect these conditions have on rates of transpiration and photosynthesis, as well as the effects upon stomatal aperture (Fernández 2013; Schönherr 2001).

The exact composition of the fertiliser applied will also have distinct effects on nutrient uptake at the leaf surface, primarily dependent upon the exact nutrient that is being provided. Whilst all essential elements should be able to pass through the leaf cuticle, translocation to other regions of the plant may not be possible (Wittwer 1969). Translocation in the leaf is predominantly through the apoplastic or symplastic pathway; either through the extracellular material and the cell wall, or through the cell cytoplasm via plasmodesmata, respectively (Fernández, $2013 \# 14$ ). It has been shown that the rate of translocation within plant tissues differs between each essential nutrient, with $\mathrm{Cl}, \mathrm{Na}, \mathrm{K}$ and $\mathrm{N}$ being considered more mobile than $\mathrm{Fe}$, and Ca being conditionally mobile (Bukovac 1957). This may be associated with the charge in the ionic form of the nutrient in solution, due to accumulations 
of negative charges within the plant apoplast. Foliar fertilisers often contain a number of complementary components in addition to the nutrient content, that are added to aid the absorption process. Wetting agents, or surfactants, reduce the surface tension of the solution and allow maximum dispersal across the foliage, thus utilising the entire surface area of the crop wherever possible (Tanq 2007). Furthermore, agents to enable penetration can be applied to improve uptake through the cuticle, $\mathrm{pH}$ modifiers can be used to alter the ionic composition of specific nutrient and thus aid uptake, humectants are used to prolong the drying process, and adjuvants are utilised to extend the time the fertiliser remains on the leaf surface, preventing run off in wet conditions (Stevens 1994).

The cuticle is the primary site of nutrient uptake via foliar sprays and therefore its composition is a significant factor in the rate of nutrient uptake (Riederer 1995). The composition of the epicuticular wax is variable between crop species, as is the leaf surface area and as such, the efficiency of a foliar fertiliser can be variable across agricultural applications. The presence of leaf trichomes, hair-like projections on the leaf surface, and their relative compositions may also impact plant surface wettability and thus the surface available for uptake (Kannan 1986). In addition, the stage of leaf development, will play a role in uptake, as will the general tissue and plant health.

These are just some of the factors contributing to the variable efficacy of foliar fertilisers, limiting this method of nutrient supplementation as a direct replacement of soilbased fertilisers (Mengel 2001). However, a step change in fertiliser technology, or the development of rapid screening methods to assess the potency of foliar fertiliser may increase the adoption of this approach. One such method that may be able to contribute to nutrient uptake studies is Raman microspectroscopy. Based on the phenomena of inelastic light scattering, Raman microspectroscopy is a highly sensitive technique that can be used to detect and monitor single molecules by observing the interaction of light with the chemical 
bonds within a sample (Kneipp 1999). The occurrence of Raman scatter is an inherently low probability process, which can be problematic in samples with intrinsic fluorescence, such as plants, where Raman information can be swamped by stronger fluorescence signals (Butler 2016). The development of alternative Raman modes such as stimulated Raman spectroscopy has helped overcome some of these restrictions to plant based applications. In addition, it has recently been shown that spontaneous Raman can be applied in vivo to derive spectral information from leaves, due to the quenching effect of water found ubiquitously through the plant (Mansfield 2013; Littlejohn 2015; Butler 2015).

In this study, we employ Raman microspectroscopy as a novel method of monitoring nutrient uptake at the adaxial leaf surface using tomato (Solanum lycopersicum) as a model plant species, complemented by ion probe and flame atomic absorption spectroscopy (FAAS) measurements that are used conventionally. The application of $\mathrm{CaNO}_{3}$ is presented as preliminary example of nutrient uptake monitoring of two essential macronutrient required for successful plant growth; directly measuring the $\mathrm{NO}_{3}$-component of the nutrient salt, and the possibility of indirect ion monitoring of Ca. Low availabilities in these molecules can result in deficiencies that are known to manifest across a range of crop species and cause significant yield losses (Simon 1978). Foliar nutrient supplementation is one way in which such deficiencies have been combatted, however the mechanism by which foliar Ca sprays are able to improve a crops tolerance to nutrient stress is not fully understood given variable mobility of different molecules (Van Goor 1971; Wada 1996; Geraldson 1957). Our aim is to use the three-pronged Raman microspectroscopy, ion probe and FAAS approach in order to observe and potentially quantify $\mathrm{NO}_{3}$ - uptake at the leaf surface. This will present a novel assay for assessing the efficacy of a foliar fertiliser, by observing its rate of uptake and subsequent mobility within the plant. 


\section{Methods}

\section{Nitrate salt characterisation}

In order to investigate the uptake of $\mathrm{NO}_{3}$ - at the leaf surface, $\mathrm{Ca}\left(\mathrm{NO}_{3}\right)_{2}$ was chosen as a model compound due to its widespread use in agriculture as both a $\mathrm{Ca}$ and nitrate fertiliser, and as well as its distinct Raman vibrational modes. $\mathrm{Ca}\left(\mathrm{NO}_{3}\right)_{2}$ at $99 \%$ reagent grade (SigmaAldrich Ltd, Dorset, UK) was characterised using an InVia Raman spectrometer with a 785 nm excitation laser and charge coupled device (CCD) detector (Renishaw Plc, Gloucestershire, UK) with a microscope attachment (Leica Microsystems, Buckinghamshire, UK). Spectral calibration was conducted using a silicon source prior to spectral acquisition. $500 \mathrm{mg}$ of solid $\mathrm{Ca}\left(\mathrm{NO}_{3}\right)_{2}$ was applied onto an Au-coated slide (Platypus Technologies, WI, USA); even pressure was applied to produce a flattened surface for analysis. This was repeated three times for each sample, with 10 spectra obtained per repeat. A $1 \mathrm{M}$ $\mathrm{Ca}\left(\mathrm{NO}_{3}\right)_{2}$ solution was prepared using Milli-Q filtered water up to a volume of $500 \mathrm{~mL}$ for increased accuracy. To investigate the effects of Ca chelation, ethylenediaminetetraacetic acid (EDTA) was prepared at 1, 0.5 and $0.25 \mathrm{M}$ using filtered water, and this was mixed 1:1 with $1 \mathrm{M} \mathrm{Ca}\left(\mathrm{NO}_{3}\right)_{2}$., resulting in $0.5 \mathrm{M} \mathrm{Ca}\left(\mathrm{NO}_{3}\right)_{2}$-EDTA solution. For each solution, $50 \mu 1$ was applied onto an Au-coated slide and 10 spectra were obtained per solution, with each solution repeated three times. Spectra were obtained using a 50× magnification $(0.75$ numerical aperture), $1200 \mathrm{~mm}-1$ grating, $50 \%$ laser power (13 $\mathrm{mW}$ at the sample) and a 10 second exposure time. Spectra were visualised across the $2000-500 \mathrm{~cm}-1$ region, accounting for regions of overlap with plant associated vibrational modes, using Matlab 2016a software (The Math Works, MA, USA).

\section{Plant growth conditions}


The tomato plant, Solanum lycopersicum cv. Moneymaker (Moles Seeds, Essex, UK), was chosen as a model species to observe nutrient uptake at the leaf surface due to its susceptibility to nutrient deficiencies, including the Ca deficiency 'blossom end rot', as well as their relatively fast growth rate. This crop variety had been previously used in spectroscopic studies and had been shown to display no signs of damage following Raman interrogation (Butler, 2015 \#25). Seeds were germinated in M3 compost (Levington Horticulture, Suffolk, UK) and watered daily in a controlled environment growth room with relative light intensity of $150 \pm$ $\mu \mathrm{mol} \mathrm{m}-2 \mathrm{~s}-1$ provided by $600 \mathrm{~W}$ metal halide lamps (Osram Ltd, Merseyside, UK) with a $16 \mathrm{~h}$ / $25 \pm 2{ }^{\circ} \mathrm{C}$ day, $8 \mathrm{~h} / 20 \pm 2{ }^{\circ} \mathrm{C}$ night cycle. To account for time dependent alterations in rates of $\mathrm{CO}_{2}$ and $\mathrm{H}_{2} \mathrm{O}$ assimilation that may affect nutrient translocation, all experimentation was conducted at midday, at the middle of the set light period, where the plants were assumed to be at a stable rate of photosynthesis. Plants were grown for 8 weeks following germination, before being selected for this study.

\section{Raman Microspectroscopy and Ion Probe measurements}

An overview of the experimental procedure is illustrated in Figure 1. In brief, the uptake of six $\mathrm{Ca}\left(\mathrm{NO}_{3}\right)_{2}$ solutions at defined concentrations of $0,5,10,15,20$ and $25 \mathrm{mM}$ were monitored using parallel Raman microspectroscopy and ion probe measurements. A circular banded area, $1.77 \mathrm{~cm} 2(r=0.75 \mathrm{~cm})$, was isolated using silicone grease and all treatments were applied to this defined area throughout. Due to the possibility of silicone diffusion in the cuticle, the volume of grease was restricted to less than $1 \mathrm{~mm}$ in thickness to prevent altering of physical-chemical nature of the banded areas. A total of 60 plants were used for this study; 10 per nutrient treatment. On each plant, five leaflets were banded and used for this study.

Only mature leaflets of a similar morphological stage were chosen, as these were fully expanded and less prone to movement resulting in treatment run-off. Throughout this study, live plant systems were analysed and no leaflets were removed at any point. 
All solutions were prepared using Milli-Q water, a calibrated balance and made up to volumes of $500 \mathrm{~mL}$. All solutions contained $0.01 \%$ Silwet L-77 wetting agent (de Sangosse Ltd, Cambridgeshire, UK), to optimise spread of the nutrient solution across the banded area, which was shown in preliminary studies to reduce variability with uptake across the leaf surface. An InVia Raman spectrometer with Leica microscope attachment was used to obtain Raman spectra, using a 50× objective, $1200 \mathrm{~mm}-1$ grating, 50\% laser power, and a 15 second exposure time. A minimum of 5 spectra was obtained per sample, spanning across the whole of the banded area. LAQUAtwin compact $\mathrm{Ca}_{2}+$ and a $\mathrm{NO}_{3}-$ meters (Horiba Instruments Ltd, Northamptonshire, UK; models B-751 and B-741 respectively) were used as ion-selective electrodes, to monitor alterations in these ions. Each probe was washed with deionised water between all measurements.

Initially, a control Raman measurement was taken from four randomly chosen leaflets at $\mathrm{T}_{0}$ to derive the plant biochemical fingerprint prior to nutrient application. Immediately following this, the $30-\mu \mathrm{L}$ treatment was applied onto the leaf surface within the banded area. This volume was chosen as it sufficiently covered the banded area without weighting down the leaflet, therefore preventing run-off. On four randomly selected leaflets, this solution was aspirated off the leaflet after 30 seconds and analysed using the ion-selective probes.

Timepoint $\mathrm{T}_{0}$ therefore represents a control measurement, as it is assumed that significant absorption does not occur in the subsequent 30 second interval. Once a leaflet had been analysed, it was excluded from the study. The solutions were then allowed to dry overnight. The following day (T24), 24-hours post the initial Raman measurement, a second Raman measurement was obtained from a further four randomly selected leaflets. In order to resuspend any remaining $\mathrm{Ca}\left(\mathrm{NO}_{3}\right)_{2}$ upon the leaflet, $30 \mu \mathrm{L}$ of distilled water was applied and gently dispersed across the banded area. The contribution of this to treatment concentration is small to quantify accurately, and so rehydration of the remaining $\mathrm{Ca}\left(\mathrm{NO}_{3}\right)_{2}$ was maintained at 
$30 \mu \mathrm{L}$ and compared against measurements made from reference materials, glass and plastic, that were conducted in parallel. Again, the solution on four leaflets was aspirated from the surface 30 seconds following $\mathrm{H}_{2} \mathrm{O}$ application, and analysed using the ion probes. This process of Raman interrogation followed by rehydration of the banded area and subsequent ion probe measurement was repeated at $\mathrm{T}_{48}$ and $\mathrm{T}_{72,48}$ - and 72 -hours post initial application respectively.

At each time point, four leaflets were chosen at random across the sample cohort for Raman analysis, and a further four were used for ion probe measurements. Therefore, of the total 50 leaflets initially selected for study (10 plants $\times 5$ leaflets $)$ in each treatment group, a minimum of 36 leaflets were analysed per treatment across the 72 -hour period. This resulted in a dataset containing over 1080 spectra (36 leaflets $\times 6$ treatments $\times 5$ spectra).

\section{Tissue digestion and FAAS}

Following analysis across the four time points using Raman microspectroscopy and ion probe measurements, a selection of the remaining leaflets were analysed using FAAS in order to determine the overall Ca content of the tissue. FAAS is a common analytical method of determining elemental content of plant tissue, and has been used routinely to monitor crop nutrient status (Harborne, 1998 \#65). Elemental analysis on Ca was conducted in order to determine if previously attained results provided more information regarding $\mathrm{Ca}$ transportation than this commonly used method. Leaflets were excised from the plant and washed thoroughly using deionised water to ensure any residual treatment was adequately removed. The 'banded area' from each leaflet was isolated from the 'remaining' area using a scalpel, and both tissues were dried at $80^{\circ} \mathrm{C}$ in a drying oven for 3 days in order to remove all water content. This tissue was then homogenised into a fine powder, and the total mass was recorded. Each sample was digested in $10 \mathrm{~mL}$ concentrated, trace metal grade $\mathrm{HNO}_{3}$ (Sigma- 
Aldrich Ltd, Dorset, UK) at $200^{\circ} \mathrm{C}$ on a digital hot plate (Bibby Scientific Ltd, Staffordshire, UK; SD500), in a volumetric flask sealed with a 'bubble top', to allow reflux of the acid for a minimum of $2 \mathrm{~h}$ and to guarantee complete digestion. When digestion was complete, the tops were removed and the $\mathrm{HNO}_{3}$ was allowed to evaporate until near dryness, when the samples were then removed from heat. The residual material was re-dissolved in $<5 \mathrm{~mL}$ of $5 \% \mathrm{HNO}_{3}$ and $0.5 \mathrm{~mL}$ of $1 \% \mathrm{LaCl}_{3}$ was added to ensure full $\mathrm{Ca}$ release from the material. This solution was then filtered using a Whatman® 541 hardened, ashless filter paper (Fisher Scientific, Leicestershire, UK), and made up to standard volumes of $25 \mathrm{~mL}$.

These digested samples were then analysed using an AAnalyst 200 flame atomic absorption spectrometer (Perkin Elmer, MA, USA) with acetylene gas, compressed air and a Ca-Mg lamp (422.7 nm) to provide an absorbance value corresponding to a Ca concentration, as determined by a calibration curve obtained prior to acquisition. Absorbance above 0.4 arbitrary units $(\mathrm{au})$ is considered outside of the linear range of detection for the spectrometer, and thus any samples reading above this value were diluted accordingly; as a result, the majority of samples were diluted 1 in 50. Three replicates were taken per sample, with a read delay of three seconds. Absorbance values were converted to ppm using a calibration curve, and subsequently $\% \mathrm{Ca}$ values were derived by multiplying by the dilution factor, and the total volume, and dividing this by the mass of homogenised sample initially used.

\section{Data Analysis}

Unless otherwise stated, Raman spectra were processed using the IRootLab toolbox for Matlab (Trevisan 2013). All spectra were initially cut to $1700-500 \mathrm{~cm}-1$ as this region encompassed all biological information from the leaf samples as well as any overlapping $\mathrm{Ca}\left(\mathrm{NO}_{3}\right)_{2}$ vibrational modes. For the purpose of comparison between these two samples, a polynomial baseline correction was conducted in order to maintain the conventional 
morphology of a Raman spectrum, whilst reducing any residual background fluorescence that can commonly occur when analysing plant materials with intrinsic fluorescence (Butler, 2016 \#24). It is worth noting, that live plant tissues have been shown to have reduced susceptibility to fluorescence, associated with the high water content and potential quenching effect (Butler, 2015 \#25). To characterise the vibrational modes of $\mathrm{Ca}\left(\mathrm{NO}_{3}\right)_{2}$ spectra, a second order derivative (with Savitzky-Golay noise reduction) was conducted followed by vector normalisation and a wavelet denoising, in order to effectively highlight subtle differences in the scattering intensity of each solution at the $780-680 \mathrm{~cm}-1$. Spectra obtained during treatments were second order differentiated, with vector normalisation and wavelet denoising. A second order derivative was chosen so that the peak centroid could be obtained, and a Raman scattering intensity value at a specific wavenumber could be derived that was reflective of the original spectrum, whilst still benefitting from background elimination. Multivariate analysis was conducted using in house developed protocols within Matlab. Partial least squares analysis was deemed the most suitable technique for this application as it lends itself to quantitative applications.

One-way analysis of variance (ANOVA) with Tukey's multiple comparison tests were conducted in GraphPad Prism 4 software (GraphPad Software Inc, CA, USA). All figures were also produced using Prism 4 software.

\section{Results \& Discussions}

\section{$\mathrm{Ca}\left(\mathrm{NO}_{3}\right)_{2}$ characterisation}

Numerous studies have been conducted to characterise solid and aqueous forms of $\mathrm{Ca}\left(\mathrm{NO}_{3}\right)_{2}$ using Raman spectroscopy, of which four distinct vibrational modes have been deduced: a double degenerate mode at $1400 \mathrm{~cm}-1$, a symmetric stretch at $1050 \mathrm{~cm}-1$, a double degenerate mode at $720 \mathrm{~cm}-1$, as well as a Raman inactive band at $830 \mathrm{~cm}-1$ (Irish 1967; Hester 1964; 
Balshaw 1975; Nyquist 2012). These same modes were visible in this study, in both solid and aqueous forms (Figure 2). The peak at $1050 \mathrm{~cm}-1$ is synonymous with $\mathrm{NO}_{3}$ - stretching and show a clear concentration effect when observing a varying range of $\mathrm{Ca}\left(\mathrm{NO}_{3}\right)_{2}$. The subtle peak at the $720 \mathrm{~cm}-1$ region is intriguing as it may provide further details towards the physical state of the compound and its related ions. In solution, this peak is known to split into 743 and $719 \mathrm{~cm}-1$, associated with 'bound' and 'free' NO3- respectively (Balshaw 1975). Bound $\mathrm{NO}_{3}$ - refers to the $\left[\mathrm{CaNO}_{3}\right]_{+}$complex, whilst free is related to $\mathrm{NO}_{3}$ - interaction with $\mathrm{H}_{2} \mathrm{O}$ (Hester, 1964 \#41).

The Raman spectrum of a S. lycopersium leaf is also shown, as well as the consequent spectra following application of $1 \mathrm{M} \mathrm{Ca}\left(\mathrm{NO}_{3}\right)_{2}$ solution upon the adaxial surface. The $v_{\text {sym }}\left(\mathrm{NO}_{3}\right)$ - can be seen strongly additional to the underlying plant spectrum, where there would be potential overlap with $v(\mathrm{CO})$ and $\delta(\mathrm{CO})$ modes of leaf polysaccharides (Movasaghi 2007); however, no specific Raman band within plant tissues is known to be present at this specific wavenumber (Sene 1994; Schulz 2007). There is also evidence of a $\mathrm{Ca}\left(\mathrm{NO}_{3}\right)_{2}$ peak at around $740 \mathrm{~cm}-1$, although there is thought to be some overlap in this region with chlorophyll scattering (Schrader 1999).

Despite some overlap, this investigation shows the capability to detect trace residues of $\mathrm{Ca}\left(\mathrm{NO}_{3}\right)_{2}$ upon the leaf surface, through monitoring scattering associated predominantly with the $\mathrm{NO}_{3}$ - component of the compound. As this is a common component of commercial fertilisers, the ability to monitor uptake of this key nutrient would be beneficial for fertiliser development. As $\mathrm{Ca} 2+$ ions would not have a Raman signature, we also investigate the possibility that $\mathrm{NO}_{3}$ - may be an indirect indicator of the presence of $\mathrm{Ca}$. To this end, we investigated the effect of the Ca chelator EDTA, at this lower wavenumber region in order to determine whether $\mathrm{Ca}$ can be monitored via $\mathrm{NO}$ 3- peaks. EDTA will essentially sequester $\mathrm{Ca} 2+$ ions and thus it was predicted that in its presence there should be a higher proportion of 
free $\mathrm{NO}_{3}$ - in solution. Figure 3 illustrates $\mathrm{Ca}\left(\mathrm{NO}_{3}\right)_{2}$ solutions in the presence of EDTA in the $780-690 \mathrm{~cm}-1$ region, encompassing the bound and free $\mathrm{NO}$ - bands. In the absence of EDTA, the peak at $719 \mathrm{~cm}-1$ has a higher Raman intensity (represented as more negative in a second derivate spectrum) than the peak at $743 \mathrm{~cm}-1$ highlighting that $\mathrm{NO}_{3}$ - is found both in complex with $\mathrm{Ca} 2+$ ions as well as a free ion. As EDTA is added, the relationship between these two peaks alters, with a reduction in bound $\mathrm{NO}_{3}$ - peak and an increase in the free peak at $719 \mathrm{~cm}-1$. The ratio between these two peaks increases with the addition of EDTA, suggesting that more $\mathrm{NO}_{3}$ - is released into the solution as $\mathrm{Ca} 2+$ complexes with EDTA. This indicates that the theoretical loss of $\mathrm{Ca} 2+$ ions mimicked by the addition of EDTA, can be monitored indirectly by observing $\mathrm{NO}_{3}$ - associated Raman bands.

\section{Raman spectroscopy as a monitor of nutrient uptake}

The ability of Raman spectroscopy to determine the presence of $\mathrm{NO}_{3}-$ on the leaf surface was initially demonstrated using a $1 \mathrm{M}$ solution of $\mathrm{Ca}\left(\mathrm{NO}_{3}\right)_{2}$; a relatively high concentration in regards to standard nutrient fertiliser compositions. Determining an agriculturally relevant concentration range is challenging as application levels are dependent upon the manufacturer of choice, as well as the growers own preference. Commercially available Ca fertilisers are sold as stock solutions, often containing between 5-30\% Ca w/v, and have varied recommended dilution levels ( 1 in 50-500) (Ochiman 2012). The concentration range used in this study was based upon recommended values and previous studies into fertiliser efficacy (Domagała-Świątkiewicz 2009; Peyvast 2009; Syahren 2012; Murillo-Amador 2006).

Following the experimental procedures previously defined, Raman spectral measurements were obtained from the adaxial leaf surface, following treatment with six $\mathrm{Ca}\left(\mathrm{NO}_{3}\right)_{2}$ treatments $(0,5,10,15,20,25 \mathrm{mM})$ over a 72-hour time course $\left(\mathrm{T}_{0}, \mathrm{~T}_{24}, \mathrm{~T}_{48}, \mathrm{~T}_{72}\right)$. Figure 4 represents the Raman scattering intensity at the $v_{\operatorname{sym}}\left(\mathrm{NO}_{3}\right)$ - region $(1050 \mathrm{~cm}-1)$ at each time 
point, in order to compare each treatment and determine a concentration dependent effect. At $\mathrm{T}_{0}$, no treatment has been applied and is therefore an indicator of generic variance between each sample. Some slight differences are apparent between each of the samples that may be due to slight differences in leaf age, but importantly no treatment pattern is observed at this time point. Raman spectra obtained at $\mathrm{T}_{24}$ depict the leaf surface following application of each treatment and subsequent drying, and should therefore represent the time point when the concentration gradient should be most evident.

The Raman intensity at $1050 \mathrm{~cm}-1$ overall show an upward trend with increasing $\mathrm{NO}_{3}-$ concentration, with the two highest treatments, 20 and $25 \mathrm{mM}$, displaying the most significant differences. Although the $10 \mathrm{mM}$ treatment is not statistically significant, there is an overall increase in the mean that obeys the concentration gradient. The interquartile range between treatments is relatively consistent, whereas the upper extremes are considerably more variable, indicating that there are numerous intensity values that are higher than the mean of each data point. Such variability between data points may indicate that residual $\mathrm{Ca}\left(\mathrm{NO}_{3}\right)_{2}$ upon the leaf surface is not spread evenly across the leaf surface. At $\mathrm{T}_{48}$, this concentration gradient is still visible, however at a lower intensity than the previous time point, and only statistically significant at 15,20 and $25 \mathrm{mM}$ treatments. This suggests that there is still nitrate salt remaining upon the leaf surface, but that some has been absorbed through the cuticle into the underlying tissue.

The data range within each treatment also supports this there are fewer extreme data points associated with areas of high $\mathrm{NO}_{3}-$ and $\mathrm{Ca}$ content. The final time point, $\mathrm{T} 72$, displays some indication of a concentration effect, although at lower levels of significance, and with much variability between treatments. In contrast to $\mathrm{T}_{24}$, the upper extremes for all treatments are almost equivalent, whereas lower extremes depict the greatest differences, possibly the reason for the statistical difference between 15 and $20 \mathrm{mM}$ treatments. As there is some 
overlap at the $1050 \mathrm{~cm}-1$ peak with plant polysaccharides, this lower limit may be indicative of slight differences in the leaf age, as older leaves are known to have increased levels of cellulose due to cell wall development (Butler 2015; Monti 2013). The spectral intensity values are parallel with $\mathrm{T}_{0}$ measurements, showing a reduction in the Raman scattering over time, indicating that the majority of the remaining of $\mathrm{Ca}\left(\mathrm{NO}_{3}\right)_{2}$ on the leaf surface 72 hours post application.

As alternative view through the data, Figure 5 displays each individual treatment monitored over the 72-hour period, in order to show a rise in $\mathrm{NO}_{3-}$ on the leaf surface following application and a sequential decline, indicative of uptake. The control treatment, 0 $\mathrm{mM}$ presents some distinct variance between each time point, which consequently shows the typical range of Raman scattering intensity at $1050 \mathrm{~cm}-1$, likely attributed to the normal variance between distinct leaflets. 5 and $10 \mathrm{mM}$ treatments, display very small increases in scattering range at $\mathrm{T} 24$, post- application, but not to an extent significantly different to that of the overall variance shown in the $0 \mathrm{mM}$ treatment. At the higher concentrations, 15, 20 and $25 \mathrm{mM}$ however, there is a much more marked increase from $\mathrm{T}_{0-24}$, when focusing on the range of intensity values derived, a successive decrease over the remainder of the time course. Although, the higher of these treatments does not depict this pattern to the same extend as 15 and $20 \mathrm{mM}$, there is still some subtle time dependent alterations, showing potential uptake of $\mathrm{NO}_{3}$ - and $\mathrm{Ca}$ at the leaf surface.

When observing purely the mean of all the data points, the time related pattern of an increase in absorbance between $\mathrm{T}_{0}$ and $\mathrm{T}_{24}$ and then a progressive reduction at $\mathrm{T}_{48}$ and $\mathrm{T}_{72}$, is not shown significantly and suggests that the information specific to $\mathrm{NO}_{3}$ - uptake is relatively inconsistent. This may be due uneven drying on the leaf surface of $\mathrm{Ca}\left(\mathrm{NO}_{3}\right)_{2}$ despite the addition of a wetting agent, that is subsequently resulting in salt deposits at distinct locations. Additionally, the overlap of the $1050 \mathrm{~cm}-1$ with underlying plant cell components, such as 
cellulose, may influence the reproducibility of the spectra derived. Although leaflets of a similar morphological stage were chosen, small differences in growth rate, position and general health would have significant impacts on the spectral baseline of this study. There is also the possibility that by providing increased $\mathrm{Ca}\left(\mathrm{NO}_{3}\right)_{2}$ to the area, there may be some stimulatory effects on cell growth; however, the relatively short time frame makes this suggestion unlikely.

The Raman peak at $743 \mathrm{~cm}-1$, corresponding to bound NO3-, are apparent within the leaf spectral fingerprint following foliar application of $\mathrm{Ca}\left(\mathrm{NO}_{3}\right)_{2}$ in a region where only broad underlying Raman bands were visible. Therefore to observe uptake, spectral intensities from this band were extracted and analysed using the same approach as shown previously with the $v_{\text {sym }}\left(\mathrm{NO}_{3}\right)$ - region. Initially, it is evident that a concentration dependent relationship can be seen at $\mathrm{T} 24$, highlighting that following application of the nutrient treatment the residual $\mathrm{Ca}\left(\mathrm{NO}_{3}\right)_{2}$ salt can be monitored on the leaf surface (Figure 6). Interestingly, the range of values is noticeably less than portrayed in $1050 \mathrm{~cm}-1$ values, potentially inferring that this peak is less prone to reproducibility issues.

Mean values of these data further support this relationship, which show a clear upwards trend. This could be attributed to the lack of overlap with other scattering bands, particularly those which are sensitive to morphological differences, such as the $1050 \mathrm{~cm}-1$ peak. The control time point $\mathrm{T} 0$, shows the expected variance from the $743 \mathrm{~cm}-1$ band and as anticipated, no concentration effects are evident. At $\mathrm{T}_{48}$, the scattering intensity increases in a concentration dependent manner, to an extent not dissimilar to that of $\mathrm{T}_{24}$, suggesting that $\mathrm{NO}_{3}$ - absorption is low between these two time points. It is more likely in reality that this artefact is due to inconsistency in the Raman spectra, rather than a reduced absorption rate, which is later clarified by data from ion selective probes. At T72, there is also residual evidence of the nitrate salt treatment indicated by significant differences in the intensity of 
values for 15, 20 and $25 \mathrm{~cm}-1$, although closer to the intensities displayed at To. A distinctly higher lower limit for the data points may be responsible for the significant differences shown, which again may occur due to the spectral baseline from the leaf itself. This spectral region is where DNA associated bond vibrations occur, as well as contributions from chlorophyll (Movasaghi 2007). The latter of these molecules could be found at differing levels within tissues of varying ages, morphologies and growth status in relation to their photosynthetic capability (Antoniaa 2005). The application of fertiliser could also have a direct effect on chlorophyll content in plant cells, corresponding to elevated scattering intensities seen in higher treatments (Jianfeng 2015).

In contrast, when comparing individual treatments over the 72-hour time course, the pattern of nutrient uptake is not as clear as earlier observations, even at higher concentrations (Figure 7). The first slight indication of an increase in scattering intensity from $\mathrm{T}_{0}$ to $\mathrm{T}_{24}$ is only evident in the $25 \mathrm{mM}$ treatment, and even so, this effect is not significant across the four time points. This could be largely attributed to the relatively high intensity of the $\mathrm{T}_{0}$ measurements, which is mimicked across nearly all of the different treatments, including the control. This suggests at this particular time point, regardless of foliar $\mathrm{Ca}\left(\mathrm{NO}_{3}\right)_{2}$ application, the starting Raman intensity at $743 \mathrm{~cm}-1$ was higher than at the end of the study. As this peak can be associated with chlorophyll, this may be due to a heightened rate of photosynthesis on this particular date, despite the environmental conditions within the glasshouse being actively controlled (Zeiri 2007).

The selection of specific wavenumbers associated with the chemical treatment can be defined as a univariate approach; where a single variable, i.e. wavenumber, is analysed. For this application, a univariate approach was considered optimum as the molecule being monitored $\left(\mathrm{Ca}\left(\mathrm{NO}_{3}\right)_{2}\right)$ has a distinctive Raman spectral profile that can be identified 
supplementary to a background leaf spectrum. However, the field of vibrational spectroscopy has hugely benefitted from multivariate approaches, where the entire spectrum is used for analysis, thus revealing subtle biochemical changes. Such examples of this are principal component analysis (PCA) and partial least square analysis (PLS), where the spectra are transformed into new variables that account for spectral variance (Jolliffe 2011). The latter of these is particularly suited for quantitative analysis, allowing linear models of complex datasets (Haaland 1988).

PLS analysis of Raman spectra derived from this study was explored as alternative analysis for monitoring nutrient uptake (Figure 8). PLS variable scores are plotted to display distribution, with separation on the y-axis indicative of spectral differences, and overlap indicating spectral similarity. At the control time point $\left(\mathrm{T}_{0}\right)$, there are some significant differences between the plant of different treatments, as previously seen with univariate approaches at 743 and $1050 \mathrm{~cm}-1$. After subsequent application of $\mathrm{Ca}\left(\mathrm{NO}_{3}\right)_{2}$ onto the leaf surface $\left(T_{24}\right)$, the differences in the treatment groups are accentuated, with significant differences occurring with increasing concentrations. Higher concentration treatments tend to appear more negative in the first PLS variable. This is also shown at the T48 time point, where the highest three treatments still show significant differences compared to the control. Interestingly, these differences are shown to almost the same degree as the previous time point, insinuating that there is less uptake at the leaf surface, or that spectral measurements are variable. The latter appears most likely, due to the larger range of error evident at this time point. Differences are further reduced after 72-hours, as expected with gradual $\mathrm{NO}_{3}-$ uptake.

Whilst this multivariate approach shows similarity to the previously reported univariate analyses, it might have been expected to show a more linear response to this 
concentration gradient if effective. The strong overlap between nutrient treatments, as well as variable responses, indicates that the spectral response is not as clear as required for accurate quantitative measurements at this stage. This may be due to the underlying biological variance in the leaf tissue, overshadowing the subtle chemical changes on the leaf surface.

\section{Ion selective probes to monitor $\mathrm{Ca}_{2}+$ and $\mathrm{NO}_{3}-$}

In parallel to Raman microspectroscopy measurements, $\mathrm{Ca} 2+$ and $\mathrm{NO}_{3}$ - selective probes were used to elucidate the relative quantities of each ion remaining on the leaf surface over the course of the study. Ion selective electrodes have proven useful tools within plant research, allowing the accurate measurement of ionic fluxes within plant tissues, as well as to determine ionic content of xylem sap (Newman 2001; Rothwell 2014; Boyle 2016). These standard commercial probes were utilised to measure differences in ionic content of the nutrient solution remaining upon the leaf surface in aqueous format.

Figure 9 depicts $\mathrm{NO}_{3}$ - -selective probe measurements derived from the adaxial leaf surface (A) and also from control surfaces; plastic (B) and glass (C). At To, immediately following application upon the leaf surface, the concentration determined by the probe correlated to the known concentrations of the treatment solutions $(0-2000 \mathrm{ppm})$. After drying, and subsequent Raman measurements, the banded area of the leaflet was rehydrated and reanalysed at $\mathrm{T}_{24}$. Here, there is a clear reduction in the levels of $\mathrm{NO}_{3}$ - in the eluate from the leaf surface, implying that there is less $\mathrm{NO}_{3}$ - on the leaf surface as a consequence of uptake of the foliar treatment. In comparison to this time point in both the glass and plastic controls, no alteration in the ionic content is displayed showing that this effect is specific to absorption upon the leaf surface.

The rate of $\mathrm{NO}_{3}$ - uptake was determined to be at its highest during this initial 24-hour period, with the highest concentrations showing the fastest rate of uptake (Table 1). 
Interestingly, 20 and $25 \mathrm{mM}$ treatments display an almost identical rate of $\mathrm{NO}_{3}$ - uptake that infers the maximum absorption across the leaf surface had been achieved at this concentration. After this initial time period, the levels of $\mathrm{NO}_{3}$ - remaining on the leaf continues to diminish at $\mathrm{T} 48$, at a much reduced rate, and again at $\mathrm{T} 72$, where almost all treatments are at similar resting level. This indicates that across the 72-hour time period, the majority of the applied $\mathrm{Ca}\left(\mathrm{NO}_{3}\right)_{2}$ has been actively absorbed into the leaf tissue and is no longer present upon the adaxial leaf surface.

This notion is further supported when studying results from the $\mathrm{Ca}+$ selective probe, which illustrates an almost identical pattern to the $\mathrm{NO}_{3}$ - results obtained (Figure 10). The concentration values derived from the probe again correlate with the known concentration of the foliar treatments. The overall trend of decreasing levels of $\mathrm{Ca} 2+$ in the eluate from the leaf surface over time is still evident. The rate of uptake also correlates with the aforementioned data, with the initial 24-hour time period being the point where highest rates of uptake are seen, with some evidence of a saturation point being reached at the 20 and $25 \mathrm{mM}$ concentration. Whilst the previously described Raman spectroscopy measurements showed promise for indirect monitoring of $\mathrm{Ca}$ as a nitrate salt, this data provides evidence that the uptake of $\mathrm{NO}_{3}$ - correlated accurately with the specific concentration of $\mathrm{Ca}$ on the leaf surface.

\section{FAAS to monitor nutrient uptake}

In preliminary investigations, spectroscopic measurements were taken outside of the banded area, in order to determine if nutrient supplementation resulted in an increased Ca content of the surrounding tissues. Raman spectroscopy was unable to infer any information regarding potential Ca translocation, as spectroscopic measurements in the banded area were focused upon the leaf surface, rather than penetration into the leaf tissue. The same is also true with the ion selective probe approach, which is absolutely defined to the leaf surface. 
Table 1. The overall rate of ion uptake at the adaxial leaf surface of S. lycopersicum samples determined using an ion probe following foliar application of $\mathrm{Ca}\left(\mathrm{NO}_{3}\right)_{2}$ solutions.

\begin{tabular}{|c|c|c|c|c|c|c|c|c|}
\hline \multirow{2}{*}{$\begin{array}{l}\text { Treatment } \\
(\mathrm{mM})\end{array}$} & \multicolumn{4}{|c|}{ Rate of Ca2+ uptake (ppm cm-1 h-1) } & \multicolumn{4}{|c|}{ Rate of NO3- uptake (ppm cm-1 h-1) } \\
\hline & 0-24 h & 24-48 h & 48-72 h & Overall & 0-24 h & 24-48 h & 48-72 h & Overall \\
\hline & $0.000 \pm$ & $0.003 \pm$ & $0.000 \pm$ & $0.000 \pm$ & $0.037 \pm$ & $0.000 \pm$ & $0.000 \pm$ & $0.000 \pm$ \\
\hline & 0.000 & 0.000 & 0.002 & 0.005 & 0.000 & 0.000 & 0.000 & 0.000 \\
\hline \multirow[b]{2}{*}{5} & $1.023 \pm$ & $0.084 \pm$ & $0.009 \pm$ & $1.116 \pm$ & $1.12 \pm$ & $1.011 \pm$ & $0.127 \pm$ & $2.258 \pm$ \\
\hline & 0.038 & 0.056 & 0.009 & 0.024 & 0.002 & 0.002 & 0.001 & 0.001 \\
\hline \multirow[b]{2}{*}{10} & $2.007 \pm$ & $0.183 \pm$ & $0.037 \pm$ & $2.227 \pm$ & $2.623 \pm$ & $1.678 \pm$ & $0.103 \pm$ & $4.405 \pm$ \\
\hline & 0.015 & 0.106 & 0.049 & 0.028 & 0.001 & 0.004 & 0.002 & 0.001 \\
\hline \multirow{2}{*}{15} & $2.975 \pm$ & $0.193 \pm$ & $0.223 \pm$ & $3.391 \pm$ & $5.871 \pm$ & $0.467 \pm$ & $0.308 \pm$ & $6.646 \pm$ \\
\hline & 0.044 & 0.192 & 0.109 & 0.018 & 0.002 & 0.008 & 0.005 & 0.001 \\
\hline \multirow[b]{2}{*}{20} & $3.465 \pm$ & $0.659 \pm$ & $0.287 \pm$ & $4.411 \pm$ & $7.530 \pm$ & $1.039 \pm$ & $0.965 \pm$ & $9.159 \pm$ \\
\hline & 0.078 & 0.564 & 0.284 & 0.112 & 0.003 & 0.024 & 0.012 & 0.005 \\
\hline \multirow[b]{2}{*}{25} & $3.475 \pm$ & $1.730 \pm$ & $0.171 \pm$ & $5.376 \pm$ & $7.019 \pm$ & $3.547 \pm$ & $0.450 \pm$ & $10.94 \pm$ \\
\hline & 0.174 & 0.683 & 0.171 & 0.045 & 0.007 & 0.028 & 0.008 & 0.002 \\
\hline
\end{tabular}

In order to determine whether foliar application of $\mathrm{Ca}\left(\mathrm{NO}_{3}\right)_{2}$ resulted in an increase in Ca within the leaf tissue, FAAS was employed to analyse the banded area, as well as tissue from the remaining leaflet. Increases in total $\mathrm{Ca}$ in the banded area would substantiate that applied nutrient were in fact absorbed into the plant tissue, whereas increases in the surrounding tissue would provide evidence of translocation to regions isolated from the area of foliar application. Previous literature suggests that $\mathrm{Ca}$ is immobile in plant tissues and any increases in this tissue would be unexpected (White 2003; Hanger 1979). 
Figure 11 compares the $\% \mathrm{Ca}$ content of both tissue samples across the range of $\mathrm{Ca}$ treatments applied in this study. In tissue derived from the banded area, a net gradual increase can be seen across the concentration range, as well as an over increase in variability within the data; an observation that has been highlighted by all analytical techniques used in this study. Although there are no statistically significant differences between each treatment group, this pattern in the data may suggests that some Ca has been taken into the plant tissue. In the remaining area of the leaflet however, very little difference can be observed between the $\mathrm{Ca}$ content of each treatment group. This supports the notion that $\mathrm{Ca}$ is immobile in plant tissue and is unable to translocate following foliar nutrient application, although further investigation is required to explore this. It is also worth noting that the remaining leaflet surface area was distinctly larger than that of the banded area, with as much as ten times more dried plant material available for FAAS. Such differences may dilute the already subtle Ca content alterations, if they had occurred in the tissue.

\section{Conclusion}

By better understanding nutrient uptake and translocation in crop species, we can begin to alter agricultural practises to achieve an optimum level of efficiency that will allow a sustainable supply of food for the growing population (Roy 2006). Current fertiliser procedures do not directly address the specific nutrient requirements of the plant, particularly the secondary macro-nutrients, and the micronutrient needs, which are known to be common and detrimental to crop quality in deficient conditions. In order to understand the efficacy and mechanistic action of novel bio-enhancement fertilisers, which move away from traditional NPK fertilisers, there is a need for a rapid screening tool to observe nutrient movement within plant tissues as well as to determine the effectiveness of fertiliser formulations. 
Current methods require monitoring plant or soil nutrient content post-treatment, which often require extended trials and extensive sample preparation (Jones Jr 2001).

The purpose of this study was to observe and potentially quantify nutrient uptake at the adaxial leaf surface in S. lycopersicum as a model crop using Raman spectroscopy, ionselective probes and FAAS. By employing these methods, we were able to identify time dependent uptake of $\mathrm{NO}_{3}$ - at the leaf surface at different levels of efficiency, and subsequently provide insight into indirect $\mathrm{Ca}$ uptake as part of a nitrate salt compound. Initially, Raman spectroscopy was utilised as a rapid, sensitive and non-destructive approach to detect foliar applied $\mathrm{Ca}\left(\mathrm{NO}_{3}\right)_{2}$ on the leaf surface of live plant samples. Overall uptake of $\mathrm{NO}_{3}$ - and $\mathrm{Ca}$ over time was indirectly measured through $\mathrm{NO}_{3}$ - associated vibrational modes, and consequently was able to observe a gradual depletion on the leaf surface over time, indicative of uptake. One limitation of this approach however, is that data are extremely variable due to the uneven drying of the compound across the surface area, which resulted in $15 \mathrm{mM} \mathrm{Ca}\left(\mathrm{NO}_{3}\right)_{2}$ being the detection threshold for repeatable uptake observations over time.

In order to fully establish this technique as a crop monitoring tool, specifically for the uptake of foliar nutrients, it is important to characterise the inherent variation between leaves of the same species and varying ages, as this appears to have a significant impact on the monitoring of subtle nutrient peaks. The profile of leaf aging could then be used to offset underlying spectral variance between leaf samples. Whilst this idea has been initially approached, further computational research is required for real-world applications.

One potential method to overcome the issues of reproducibility with Raman measurements, is to use an imaging approach to observe $\mathrm{Ca}\left(\mathrm{NO}_{3}\right)_{2}$ deposits within the banded area that the treatment was applied. By image mapping a smaller banded region, areas containing residual salt deposits can be identified rapidly and in a highly interpretable false 
colour image (Butler 2016). This may a useful approach to not only assess the efficiency of nutrient uptake in live plant systems, but also to assess the efficiency of fertiliser compositions. Furthermore, it could be beneficial to exploit the depth profiling capabilities of confocal Raman microspectroscopy. Such an experiment may allow the real-time monitoring of nutrient salts on leaf surface and below, simply by altering the focal plane.

The use of ion-selective probes for direct quantification of $\mathrm{Ca}\left(\mathrm{NO}_{3}\right)_{2}$ demonstrated that the concentration of a given compound could be accurately and rapidly determined on the leaf surface over time. This simple methodology proved to be a powerful adaption of these common instruments and could be readily implemented for fertiliser screening purposes, as rates of uptake can be determined and thus the efficiency of different formulations can be interrogated.

Analytical techniques such as FAAS and inductively coupled plasma mass spectrometry (ICP-MS), are two of many approaches that are able to quantify total elemental content in plant and soil tissue (Harborne 1998). However, there is a substantial sample preparation burden with such approaches, with tissue digestion steps required prior to analysis (Huang 1985; Zarcinas 1987). In this study we were able to illustrate the net movement of $\mathrm{Ca}\left(\mathrm{NO}_{3}\right)_{2}$ from the leaf surface into the leaf tissue as a consequence of foliar fertiliser application. These data were complementary to the previously acquired Raman spectroscopy and ion selective probe measurements and clarified that $\mathrm{Ca}$ was effectively being absorbed into the leaf tissue. However, the sensitivity of this approach compared to Raman spectroscopy and probe techniques was considerably less, and was unable to statistically depict differences between treatments.

Our studies show that the approaches discussed in this article provide a novel alternative for the observation and quantification of nutrient uptake at the adaxial surface of 
plant leaves, although there is still opportunity for improvements, particularly in regards to reproducibility and the detection limit of Raman spectroscopy. The efficiency of foliar fertiliser formulation could be assessed using this approach, and in doing so, this raises the possibility of elucidating the elusive mechanisms by which nutrients, including $\mathrm{Ca}$, are absorbed at the leaf surface. Furthermore, we envisage that this methodology could be used to detect nutrient deficiencies by in vivo leaf analysis, at a higher sensitivity than current techniques, and without the requirement of extensive preparation steps. The advances we report here will contribute towards the more efficient production of crops that is desperately required to meet the need for increased agricultural productivity in order to maintain global food security.

\section{List of abbreviations}

ANOVA - analysis of variance, a.u - arbitrary units, CCD - charge coupled device, EDTA ethylenediaminetetraacetic acid, FAAS - flame atomic absorption spectroscopy, PCA principal component analysis, PLS - partial least squares analysis.

\section{Declarations}

\section{Ethics approval and consent to participate}

Not applicable

\section{Consent for publication}

Not applicable

\section{Availability of data and material}

The datasets used and analysed during the current study are available from the corresponding author on reasonable request. 


\section{Competing interests}

SA is R\&D Director of Plant Impact Plc, a leading producer of novel biostimulants.

\section{Funding}

The Centre for Global Eco-Innovation are funded by the European Union Regional

Development Fund

\section{Authors' contributions}

HJB conducted experimental work and composed the manuscript. MRM, FLM, SA, MRR provided insight into experimentation and feedback on manuscript.

\section{Acknowledgements}

HJB is a member of the Centre for Global Eco-Innovation, who are funded by the European Union Regional Development Fund and mediate the collaboration between Lancaster University and Plant Impact Plc.

\section{Authors information}

This research was generated as part of a Ph.D. project between Plant Impact Plc and Lancaster University, investigating the mechanisms of novel plant fertilisers using vibrational spectroscopies.

\section{References}

Alexander, A. 1986. Optimum Timing Of Foliar Nutrient Sprays. Foliar Fertilization. Springer.

Antoniaa, L., Tompetrini, S. and Svetlanab, P. 2005. Quantification Of Pigments In Tomato Leaves Using Reflectance Spectroscopy. P. Int. Symp. Remote Sensing Environ., 31, 39-42.

Balshaw, B. and Smedley, S. I. 1975. Raman Spectroscopy Of Concentrated Calcium Nitrate Solutions At High Pressure. J. Phys. Chem., 79, 1323-1325. 
Boyle, R. K., Mcainsh, M. and Dodd, I. C. 2016. Stomatal Closure Of Pelargonium× Hortorum In Response To Soil Water Deficit Is Associated With Decreased Leaf Water Potential Only Under Rapid Soil Drying. Physiol. Plantarum, 156, 84-96.

Bukovac, M. J. and Wittwer, S. H. 1957. Absorption And Mobility Of Foliar Applied Nutrients. Plant Physiol., 32, 428-435.

Butler, H. J., Ashton, L., Bird, B., Cinque, G., Curtis, K., Dorney, J., Esmonde-White, K., Fullwood, N. J., Gardner, B. and Martin-Hirsch, P. L. 2016. Using Raman Spectroscopy To Characterize Biological Materials. Nat. Protoc., 11, 664-687.

Butler, H. J., Mcainsh, M. R., Adams, S. and Martin, F. L. 2015. Application Of Vibrational Spectroscopy Techniques To Non-Destructively Monitor Plant Health And Development. Anal. Methods, 7, 4059-4070.

Dixon, R. C. 2003. Foliar Fertilization Improves Nutrient Use Efficiency. Fluid Journal, 11, 22-23.

Domagała-Świątkiewicz, I. and Błaszczyk, J. 2009. Effect Of Calcium Nitrate Spraying On Mineral Contents And Storability Of 'Elise' Apples. Pol. J. Environ. Stud., 18, 971-976.

Fageria, N., Filho, M. B., Moreira, A. and Guimaraes, C. 2009. Foliar Fertilization Of Crop Plants. J. Plant Nutr., 32, 1044-1064.

Fernández, V. and Brown, P. H. 2013. From Plant Surface To Plant Metabolism: The Uncertain Fate Of Foliar-Applied Nutrients. Front. Plant Sci., 4, 289.

Fernández, V. and Eichert, T. 2009. Uptake Of Hydrophilic Solutes Through Plant Leaves: Current State Of Knowledge And Perspectives Of Foliar Fertilization. Crit. Rev. Plant Sci., $28,36-68$.

Geraldson, C. 1957. Factors Affecting Calcium Nutrition Of Celery, Tomato, And Pepper. Soil Sci Soc. Am. J., 21, 621-625.

Gooding, M. J. and Davies, W. P. 1992. Foliar Urea Fertilization Of Cereals: A Review. Fert. Res., 32, 209-222.

Haaland, D. M. and Thomas, E. V. 1988. Partial Least-Squares Methods For Spectral Analyses. 1. Relation To Other Quantitative Calibration Methods And The Extraction Of Qualitative Information. Analytical Chemistry, 60, 1193-1202.

Hanger, B. 1979. The Movement Of Calcium In Plants. Commun. Soil Sci. Plan., 10, 171 193.

Harborne, A. 1998. Phytochemical Methods A Guide To Modern Techniques Of Plant Analysis, Springer Science and Business Media.

Hester, R. E. and Plane, R. A. 1964. Raman Spectrophotometric Study Of Complex Formation In Aqueous Solutions Of Calcium Nitrate. J. Chem. Phys., 40, 411-414.

Hillier, J., Hawes, C., Squire, G., Hilton, A., Wale, S. and Smith, P. 2009. The Carbon Footprints Of Food Crop Production. Int. J. Agr. Sust., 7, 107-118.

Huang, C. Y. L. and Schulte, E. 1985. Digestion Of Plant Tissue For Analysis By Icp Emission Spectroscopy. Commun. Soil Sci. Plan., 16, 943-958.

Irish, D. and Walrafen, G. 1967. Raman And Infrared Spectral Studies Of Aqueous Calcium Nitrate Solutions. J. Chem. Phys., 46, 378-384. 
Jianfeng, W., Dongxian, H., Jinxiu, S., Haijie, D. and Weifen, D. 2015. Non-Destructive Measurement Of Chlorophyll In Tomato Leaves Using Spectral Transmittance. Int. J. Agr. Biol. Eng., 8, 73.

Jolliffe, I. 2011. Principal Component Analysis. International Encyclopedia Of Statistical Science. Springer.

Jones Jr, J. B. 2001. Laboratory Guide For Conducting Soil Tests And Plant Analysis, Crc Press.

Kannan, S. 1986. Physiology Of Foliar Uptake Of Inorganic Nutrients. Proceedings: Plant Sciences, 96, 457-470.

Kneipp, K., Kneipp, H., Itzkan, I., Dasari, R. R. and Feld, M. S. 1999. Ultrasensitive Chemical Analysis By Raman Spectroscopy. Chem. Rev., 99, 2957-2976.

Littlejohn, G. R., Mansfield, J. C., Parker, D., Lind, R., Perfect, S., Seymour, M., Smirnoff, N., Love, J. and Moger, J. 2015. In Vivo Chemical And Structural Analysis Of Plant Cuticular Waxes Using Stimulated Raman Scattering Microscopy. Plant Physiol., 168, 18-28.

Mansfield, J. C., Littlejohn, G. R., Seymour, M. P., Lind, R. J., Perfect, S. and Moger, J. 2013. Label-Free Chemically Specific Imaging In Planta With Stimulated Raman Scattering Microscopy. Anal. Chem., 85, 5055-5063.

Mengel, K. Alternative Or Complementary Role Of Foliar Supply In Mineral Nutrition. International Symposium On Foliar Nutrition Of Perennial Fruit Plants 594, 2001. 33-47.

Monti, F., Dell'anna, R., Sanson, A., Fasoli, M., Pezzotti, M. and Zenoni, S. 2013. A Multivariate Statistical Analysis Approach To Highlight Molecular Processes In Plant Cell Walls Through Atr Ft-Ir Microspectroscopy: The Role Of The A-Expansin Phexpa1 In Petunia Hybrida. Vib. Spectrosc., 65, 36-43.

Movasaghi, Z., Rehman, S. and Rehman, I. U. 2007. Raman Spectroscopy Of Biological Tissues. Appl. Spectrosc. Rev., 42, 493-541.

Murillo-Amador, B., Jones, H. G., Kaya, C., Aguilar, R. L., García-Hernández, J. L., TroyoDiéguez, E., Ávila-Serrano, N. Y. and Rueda-Puente, E. 2006. Effects Of Foliar Application Of Calcium Nitrate On Growth And Physiological Attributes Of Cowpea (Vigna Unguiculata L. Walp.) Grown Under Salt Stress. Environ. Exp. Bot., 58, 188-196.

Newman, I. 2001. Ion Transport In Roots: Measurement Of Fluxes Using Ion-Selective Microelectrodes To Characterize Transporter Function. Plant, Cell and Environment, 24, 114.

Nyquist, R. A. and Kagel, R. O. 2012. Handbook Of Infrared And Raman Spectra Of Inorganic Compounds And Organic Salts: Infrared Spectra Of Inorganic Compounds, Academic Press.

Ochiman, I. D. 2012. The Impact Of Foliar Application Of Calcium Fertilizers On The Quality Of Highbush Blueberry Fruits Belonging To The 'Duke'cultivar. Not. Bot. Horti. Agrobo., 40, 163-169.

Parry, M. A. J. and Hawkesford, M. J. 2010. Food Security: Increasing Yield And Improving Resource Use Efficiency. Pro. Nutr. Soc., 69, 592-600.

Peyvast, G., Olfati, J., Ramezani-Kharazi, P. and Kamari-Shahmaleki, S. 2009. Uptake Of Calcium Nitrate And Potassium Phosphate From Foliar Fertilization By Tomato. J. Hortic. For., 1, 7-13. 
Riederer, M. and Schreiber, L. 1995. Waxes: The Transport Barriers Of Plant Cuticles. The Oily Press: Dundee, Scotland.

Rothwell, S. A. and Dodd, I. C. 2014. Xylem Sap Calcium Concentrations Do Not Explain Liming-Induced Inhibition Of Legume Gas Exchange. Plant Soil, 382, 17-30.

Roy, R., Finck, A., Blair, G. and Tandon, H. 2006. Plant Nutrition For Food Security. A Guide For Integrated Nutrient Management. Fao Fertilizer And Plant Nutrition Bulletin, 16, 368.

Saleem, I., Javid, S., Sial, R. A., Ehsan, S. and Ahmad, Z. A. 2013. Substitution Of Soil Application Of Urea With Foliar Application To Minimize The Wheat Yield Losses. Soil Environ., 32.

Schönherr, J. and Luber, M. 2001. Cuticular Penetration Of Potassium Salts: Effects Of Humidity, Anions, And Temperature. Plant Soil, 236, 117-122.

Schrader, B., Klump, H., Schenzel, K. and Schulz, H. 1999. Non-Destructive Nir Ft Raman Analysis Of Plants. J. Mol. Struct., 509, 201-212.

Schulz, H. and Baranska, M. 2007. Identification And Quantification Of Valuable Plant Substances By Ir And Raman Spectroscopy. Vib. Spectrosc., 43, 13-25.

Sene, C. F., Mccann, M. C., Wilson, R. H. and Grinter, R. 1994. Fourier-Transform Raman And Fourier-Transform Infrared Spectroscopy (An Investigation Of Five Higher Plant Cell Walls And Their Components). Plant Physiol., 106, 1623-1631.

Simon, E. 1978. The Symptoms Of Calcium Deficiency In Plants. New Phytol., 80, 1-15.

Stevens, P. 1994. Formulation Of Sprays To Improve The Efficacy Of Foliar Fertilisers. N. Z. J. For. Sci., 24, 27-34.

Swietlik, D. and Faust, M. 1984. Foliar Nutrition Of Fruit Crops. Hortic. Rev.

Syahren, A. M., Wong, N. and Mahamud, S. 2012. The Efficacy Of Calcium Formulation For Treatment Of Tomato Blossom-End Rot. J. Trop. Agric. And Fd. Sc, 40, 89-98.

Tanq, M., Sharif, M., Shah, Z. and Khan, R. 2007. Effect Of Foliar Application Of Micronutrients On The Yield And Quality Of Sweet Orange (Citrus Sinensis L.). Pak. J. Biol. Sci., 10, 1823-1828.

The British Survery Of Fertiliser Practice: Fertiliser Use On Farm Crops For Crop Year 2013. 2014 The United Kingdom Statistics Authority.

Trevisan, J., Angelov, P. P., Scott, A. D., Carmichael, P. L. and Martin, F. L. 2013. Irootlab: A Free And Open-Source Matlab Toolbox For Vibrational Biospectroscopy Data Analysis. Bioinformatics, Btt084.

Van Goor, B. 1971. The Effect Of Frequent Spraying With Calcium Nitrate Solutions On The Mineral Composition And The Occurrence Of Bitter Pit Of The Apple Cox's Orange Pippin. J. Hortic. Sci., 46, 347-364.

Wada, T., Ikeda, H., Ikeda, M. and Furukawa, H. 1996. Effects Of Foliar Application Of Calcium Solutions On The Incidence Of Blossom-End Rot Of Tomato Fruit. J. Jpn. Soc. Hortic. Sci., 65, 553-558.

White, P. J. and Broadley, M. R. 2003. Calcium In Plants. Ann. Bot., 92, 487-511.

Wittwer, S. H. and Bukovac, M. 1969. The Uptake Of Nutrients Through Leaf Surfaces. Z. Pflanz.: Springer. 
Zarcinas, B., Cartwright, B. and Spouncer, L. 1987. Nitric Acid Digestion And MultiElement Analysis Of Plant Material By Inductively Coupled Plasma Spectrometry. Commun. Soil Sci. Plan., 18, 131-146.

Zeiri, L. 2007. Sers Of Plant Material. J. Raman Spectrosc., 38, 950-955. 